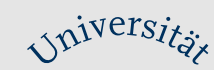

• $0_{x_{0}}$ 峲盛 Humanwissenschaftliche Fakultät

Julia Tetzner | Michael Becker

\title{
How Being an Optimist Makes a Difference
}

The Protective Role of Optimism in Adolescents' Adjustment to Parental Separation

Suggested citation referring to the original publication:

Social Psychological and Personality Science 6 (2015) 3, pp. 325-333

DOI http://dx.doi.org/10.1177/1948550614559605

ISSN (print) 1948-5506

ISSN (online) 1948-5514

Postprint archived at the Institutional Repository of the Potsdam University in:

Postprints der Universität Potsdam

Humanwissenschaftliche Reihe ; 396

ISSN 1866-8364

http://nbn-resolving.de/urn:nbn:de:kobv:517-opus4-404537 



\section{How Being an Optimist Makes a Difference: The Protective Role of Optimism in Adolescents' Adjustment to Parental Separation}

\author{
Julia Tetzner ${ }^{1,2}$ and Michael Becker ${ }^{2}$
}

\begin{abstract}
This longitudinal study of $N=1,566$ adolescents investigated the protective role of optimism in adjustment to parental separation, focusing on two salient challenges faced by adolescents, namely academic achievement and self-esteem. Based on latent change models, the results indicated associations between parental separation and short-term declines in academic achievement as well as short-term and longer term declines in self-esteem. Although optimism in general showed positive associations with academic achievement and self-esteem, its role as a protective factor proved to be particularly important for academic achievement in adjustment following parental separation.
\end{abstract}

\title{
Keywords
}

parental separation, optimism, academic achievement, self-esteem, longitudinal study

Adolescence is a time of multiple challenges and changes. On one hand, adolescents have to face multiple age-graded tasks as they grow up. On the other hand, idiosyncratic life events can have a strong impact on ontogenetic development (Baltes, Lindenberger, \& Staudinger, 2006; Brim \& Ryff, 1980; Lucas, 2007). Research from recent decades demonstrated that the separation of parents is such an idiosyncratic experience for adolescents that it is generally experienced negatively, demands substantial adjustment (for recent reviews, see Amato, 2010; Hartman, Magalhães, \& Mandich, 2011; Lansford, 2009), and can have enduring consequences even in adulthood (Fergusson, McLeod, \& Horwood, 2014). Although parental separation is usually associated with negative outcomes, young people can differ widely in their reactions (Hetherington, 2006; Hetherington \& StanleyHagan, 1999), and it is not yet fully understood which processes contribute to the variety of reactions. This study will address this important issue by highlighting the protective role of optimism in the adjustment to parental separation in two salient aspects of development during adolescence, namely academic achievement and self-esteem.

\section{Parental Separation and Developmental Trajectories During Adolescence}

Throughout adolescence, individuals have to deal with several major challenges that have lasting implications even into later adult life (Fergusson et al., 2014; Wrosch \& Freund, 2001). Most researchers agree that adolescents who experience divorce or separation of their parents are at risk for a variety of negative outcomes (for reviews, see Amato, 2010; Hartman et al., 2011; Lansford, 2009), which can include main agesalient challenges, for example, regarding academic achievement (Frisco, Muller, \& Frank, 2007; Ham, 2003; Jeynes, 2002; Menning, 2006; Sigle-Rushton, Lyngstad, Andersen, \& Kravdal, 2014) and self-esteem (Bynum \& Durm, 1996; Mandara \& Murray, 2000; Sun \& Li, 2002). Empirical studies have explained declines in developmental trajectories mainly through mechanisms such as financial problems, a lower degree of involvement of the nonresidential parent, or a reduction in supervision by resident parents (McLanahan, 1999; Menning, 2006; Pong \& Ju, 2000).

In a recent review, Amato (2010) argued that many investigations did not control for differences among adolescents prior to parental separation, and it is therefore questionable whether differences should be interpreted (at least in part) in terms of selection effects. In line with this, some studies have reported differences prior to parental separation, associated with fewer

\footnotetext{
'University of Potsdam, Potsdam, Germany

${ }^{2}$ German Institute for International Educational Research (DIPF), Berlin, Germany
}

Corresponding Author:

Julia Tetzner, University of Potsdam, Karl-Liebknecht-Str. 24/25, 14476 Potsdam, Germany.

Email: julia.tetzner@uni-potsdam.de 
financial, cultural, human, and social resources (Strohschein, 2005; Sun \& Li, 2001). In a methodologically sophisticated longitudinal study, Sun and $\mathrm{Li}$ (2002) found that students with disrupted families had lower scores on standardized achievement tests prior to their parents' marital disruption and showed further declines following the disruption. In contrast, they found a U-shaped pattern regarding psychosocial constructs such as self-esteem-a decline accompanying marital disruption and improvement following marital disruption.

\section{The Moderating Role of Optimism}

Although previous research has shown that on average, adolescents show negative outcomes associated with parental separation, young people can differ substantially in their reaction to this life event (e.g., Hetherington, 2006; Hetherington \& Stanley-Hagan, 1999). To explain this variety, recent investigations focused on the detection of protective factors that enable individuals to adjust and adapt successfully after a negative life event or significant adversity (cf. Amato, 2010). In addition to promoting factors (i.e., general beneficial effects on developmental processes), protective factors can change the impact of negative life events by interacting with them and ameliorating their negative influence (Keyes, 2004; Luthar, Cicchetti, \& Becker, 2000). So far, research has indicated moderating effects of several factors such as gender (McCabe, 1997), ${ }^{1}$ children's age (Lansford et al., 2006), ${ }^{2}$ or parental style (Vélez, Wolchik, Tein, \& Sandler, 2011). ${ }^{3}$

Over and above these demographic and contextual variables, there is a lack of research examining the role of children's personal characteristics, for example, optimism in their adjustment to parental separation. Optimism is a personality trait that is associated with a better adjustment to diverse stressors (for overviews, see Carver \& Connor-Smith, 2010; Carver, Scheier, \& Segerstrom, 2010; Nes \& Segerstrom, 2006). According to Carver and colleagues (2010, p. 879), optimists can be described as "people who expect good things to happen to them." This generalized positive approach has substantial implications for how individuals cope with adversities and stressful situations (Nes \& Segerstrom, 2006). Confronted with adverse life circumstances, optimists focus less on the negative aspects of a situation; they generally have positive expectations for the future and report less distress (Andersson, 1996; Scheier et al., 1989). After dealing with adversity, optimists are more likely to report that they have benefited from the experience in terms of personal growth (Litt, Tennen, Affleck, \& Klock, 1992). In line with this, previous studies showed associations between dispositional optimism and a better adjustment to a broad range of stressful situations such as educational transitions (Brissette, Scheier, \& Carver, 2002), the death or serious illness of a spouse (Kivimäki et al., 2005), and daily stressors (Robinson \& Liu, 2013). Building on these findings, we can assume that optimism can also help young people adjust more appropriately to the various changes and challenges associated with parental separation at this time of major transitions in their academic and emotional well-being.

\section{The Present Study}

This study investigated the protective role of optimism in the adjustment to parental separation, focusing on two salient challenges to adolescents (academic achievement and self-esteem). In doing so, this investigation aspired to contribute to the knowledge of whether and how young people overcome adversity like parental separation, especially during adolescence when youth are experiencing major transitions in their academic and emotional lives.

As a basis for addressing the moderating effects of optimism, we wanted to replicate findings regarding declines in academic achievement and self-esteem following parental separation (Hypothesis 1). The best approach to addressing this issue is through the use of a longitudinal research design in which we control for baseline measurements prior to parental separation and investigate short-term and longer term associations with this life event. We expected to find declines in developmental trajectories related to parental separation over shorter time periods in academic achievement and self-esteem. For academic achievement, we expected to find both short-term and long-term declines because of the cumulative nature of learning processes (cf. Sun \& Li, 2002). For self-esteem, we expected to find at least short-term effects of parental separation, but as some studies report recovery of self-esteem over long time spans (cf. Lucas, 2007; Sun \& Li, 2002), we treated it as an open research question whether to expect an indication of a lasting, long-term effect or a regression to the initial level.

As a main aim of this study, we explored the role optimism may play in adjusting to parental separation. We focused on general beneficial effects of optimism for developmental trajectories in academic achievement and self-esteem during adolescence and expected to find generally positive associations regarding both constructs (promoting effects, i.e., the main effect; Hypothesis 2). Moreover, and most importantly, we addressed protective effects of optimism in the context of parental separation (i.e., interaction effects; Hypothesis 3). To our knowledge, no previous study investigated whether optimism acts as a protective factor (i.e., an interaction) for adjustment to parental separation during adolescence. Yet, recent investigations indicated moderating effects of optimism for coping with other life events (e.g., Robinson \& Liu, 2013). We hypothesized that optimism is beneficial for adjustment to parental separation because individuals with a high level of optimism should have more positive and fewer negative expectations about possible changes following parental separation and should therefore show less decline in academic achievement and self-esteem.

\section{Method}

\section{Participants}

We used a subset of data from the German longitudinal study "Learning Processes, Educational Careers and Psychosocial Development in Adolescence and Young Adulthood" (BIJU; see Schnabel, Alfeld, Eccles, Köller, \& Baumert, 2002, for details). The following analyses included data from $N=$ 
1,566 adolescents (female students $=58.4$ percent) from 99 schools in Germany (158 in the vocational track of Germany's multitrack system of secondary education, 313 in the intermediate track, 139 in comprehensive schools, and 956 in the academically oriented track). The analytic sample comprised adolescents with different educational backgrounds $(64.6 \%$ of parents [father and/or mother] with at least a university entrance diploma) and socioeconomic backgrounds (highest socioeconomic status of parents: $M=49.99, S D=12.63$; Treiman-Index; Treiman, 1977). The study used three main measurement points (see Figure A1 in the appendix), that is, at the start of the 7th grade in $1991\left(t_{1}\right)$, at the end of the 7th grade in $1992\left(t_{2}\right)$, and at the end of the 10th grade in $1995\left(t_{3}\right)$. Moreover, we used additional information from a supplementary measurement point halfway through the seventh grade in $1992\left(t_{1 \mathrm{~b}}\right)$.

\section{Design and Instruments}

Developmental trajectories. To investigate developmental trajectories in academic achievement and self-esteem, we considered the same indicators at the three main measurement points (see Figure A1 in the appendix). To assess academic achievement, we used standardized achievement tests from different studies of scholastic achievement in mathematics, English, and physics scaled on a common metric using a Rasch model (for further information, see Becker, Lüdtke, Trautwein, Köller, \& Baumert, 2012). The reliabilities of the test scores were between $\alpha=.66$ and $\alpha=.88$. The indicator for self-esteem was measured by a short German version (Jerusalem, 1984; Trautwein, 2003) of the Rosenberg Self-Esteem Scale (Rosenberg, 1965). Former analyses had shown that latent correlations between the short and the long versions of the Rosenberg scale in German equaled unity (Trautwein, 2003). It contains 4 items (example item "At times I think I am no good at all"; $\alpha_{t 1}=.73$, and $\alpha_{t 2}=.81, \alpha_{t 3}=.88$ ) on a 4-point Likert-type scale $(1=$ strongly agree and $4=$ strongly disagree $)$.

Parental separation. In this study, we operationalized parents as separated if one parent moved out of the household (regardless of whether a legal divorce occurred). At all measurement points, students were asked whether they lived with both parents in the same household, and we only used data of adolescents who had reported that they lived with both parents in the same household at $t_{1}$. We were thus able to account for baseline measurements of academic achievement and self-esteem at the start of the seventh grade prior to parental separation. For investigating shorter as well as longer term effects of parental separation, we tried to provide a relatively short time slot for potential parental separation between the first and second measurement points. Therefore, we used information from an additional data collection point midway through the seventh grade $\left(t_{1 \mathrm{~b}}\right.$; see Figure A1) to divide the sample into two groups (parental separation vs. ongoing parental relationship). Students were included in the parental separation group when they reported no parental separation at $t_{1 \mathrm{~b}}$ but reported that they did not live with both parents in the same household at $t_{2}$ ( $n=72 ; 4.6 \%$; control group: $n=1,494)$. Adolescents with parents who had already been separated at $t_{1 \mathrm{~b}}$ as well as adolescents with parents who separated between the second and third measurement points $\left(t_{2}\right.$ and $\left.t_{3}\right)$ were excluded from the analyses. Likewise, we excluded participants who reported a reunification of their parents between the second and the third data collection points. With this operationalization, we obtain two clearly defined groups, that is, we compare developmental trajectories of adolescents whose parents separated between the midpoint and the end of the seventh grade with developmental trajectories of adolescents whose parents lived together over the course of the study.

Optimism. To investigate the protective role of optimism, it is necessary to use a measurement taken prior to parental separation. To this end, we also used $t_{1 \mathrm{~b}}$ to get a measurement of optimism not influenced by the event. ${ }^{4}$ We used self-ratings of the 4 items of the positively keyed subscale of the Life Orientation Test (Scheier \& Carver, 1985; German translation by WielandEckelmann \& Carver, 1989; example item "In uncertain times, I usually expect the best"; $\alpha=.70$ ) on a 5-point Likert-type scale $(1=$ strongly agree and $5=$ strongly disagree $)$.

\section{Statistical Approach}

Missing data. For our analyses, we focused on participants with complete data on parental relationship status $(N=1,566)$. The missing data in the other variables averaged $25.9 \%$. In such cases, current literature suggests replacing missing values by using multiple imputation (MI, cf. Graham, 2009; Little \& Rubin, 2002). Although MI does not rule out parameter bias entirely, it maximizes test power and reduces the risk of biased parameter estimations, in particular in combination with auxiliary variables (cf. Collins, Schafer, \& Kam, 2001). MI was carried out using the Multiple Imputation by Chained Equations package (van Buuren \& Groothuis-Oudshoorn, 2011) in the R 2.15.1 software (cf. R Core Team, 2014).

Analytical strategy. To investigate the developmental trajectories as a function of parental separation, we used multivariate latent change models for multiple groups (cf. McArdle, 2009; McArdle \& Hamagami, 2001). For this, we specified a structural model across all data collection points and all developmental domains, with one latent factor for each point and construct, and progressively tested it for measurement invariance (not shown here); all models showed a very good model fit under strong factorial measurement invariance (each comparative fit index [CFI] $>$ .95 , root mean square error of approximation [RMSEA] $<.04$, standardized root mean square residual [SRMR] $<.05$; Meredith, 1993). We used the latent variables at the three data collection points as a basis for estimating a latent baseline and difference scores model (for specification see Figure 1). More specifically, we estimated the change between baseline measurement and $t_{2}$ $\left(\Delta_{T 1}, T 2\right)$ and the change between baseline measurement and $t_{3}\left(\Delta_{T 1, T 3}\right)$. To test the impact of parental separation on 


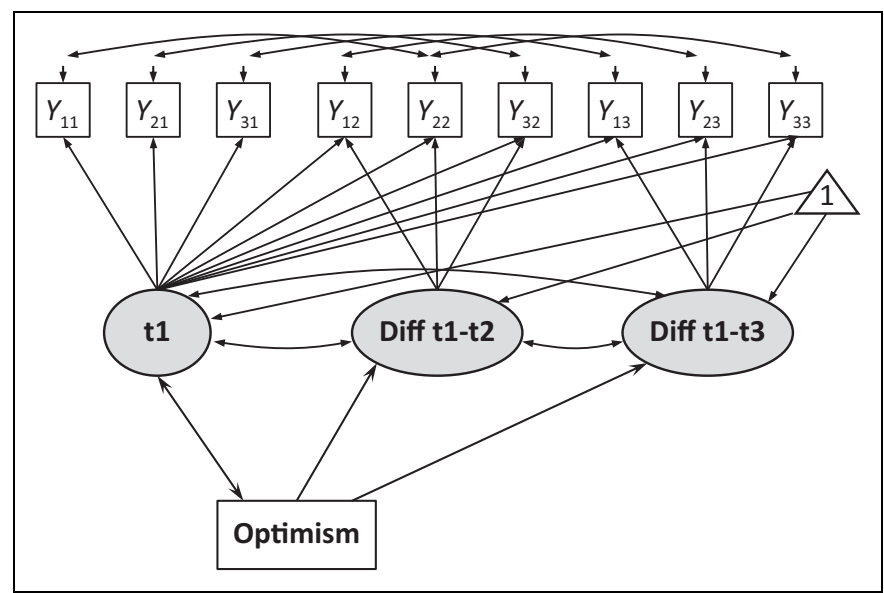

Figure I. Latent change model based on the assumption of strong factorial invariance that was estimated for each group and each life domain simultaneously.

developmental trajectories (Hypothesis 1), we estimated a multivariate latent change model for multiple groups (separation vs. nonseparation) and compared the resulting parameter estimations between these groups. Additionally, we used a multigroup model to test the effects of optimism on the developmental trajectories. We tested for the main effects of optimism (general promoting effects in the overall group, Hypothesis 2) by estimating correlations with the baseline measurements and regressions on the change scores and equating these parameter estimations between the groups (see Figure 1). Third, a multigroup model was used to test the interaction effects of optimism with parental separation on the developmental trajectories (specific protective effects, Hypothesis 3 ) by testing whether the effects of optimism differed between the groups.

We used the software Mplus 6.11 (Muthén \& Muthén, 1998-2011) for statistical modeling. All models allowed for the hierarchical data structure produced by cluster sampling (for a discussion cf. Snijders \& Bosker, 1999). We tested the significance of differences in parameter estimations using the model constraints option in Mplus.

\section{Results}

\section{Parental Separation and Developmental Trajectories}

First, we investigated the associations between parental separation and the developmental trajectories of academic achievement and self-esteem (Hypothesis 1) using a multivariate latent change model with multiple groups $(\mathrm{RMSEA}=.027$; $\mathrm{CFI}=.970$; Tucker-Lewis index $=.968 ; \mathrm{SRMR}=.048$; strong factorial invariance). We report standardized mean differences, relative to standard deviations at $t_{1}$. The results indicated differences in developmental trajectories of academic achievement as well as self-esteem as a function of parental separation (for an illustration see Figure 2): Adolescents whose parents separated during the seventh grade had already demonstrated lower academic achievement at the beginning of the seventh grade before parental separation $\left(\Delta M_{t 1}=.55\right.$, standard error $[S E]=.163, p<.001)$. Furthermore, they showed a differential decline in academic achievement during the 7th grade relative to their classmates $\left(\Delta\right.$ Diff $_{t 1, t 2}=.43, S E=.165, p=$ $.009)$ but no differential change between the 7th and 10th grades $\left(\Delta \operatorname{Diff}_{t 1, t 3}=.14, S E=.174, p=.438\right)$. Regarding self-esteem, adolescents whose parents separated during the course of the school year showed no difference in self-esteem relative to their classmates at baseline $\left(\Delta M_{t 1}=-.09, S E=\right.$ $.180, p=.611)$, but they showed a differential decline during the 7th grade $\left(\Delta \operatorname{Diff}_{t 1, t 2}=.53, S E=.217, p=.014\right)$ as well as between the 7th and 10th grades $\left(\Delta \operatorname{Diff}_{t 1, t 3}=.44, S E=\right.$ $.222, p=.049)$.

\section{The Promoting and Protective Role of Optimism}

In the second block of analyses, we tested the effects of optimism on the developmental trajectories (Hypotheses 2 and 3; results are summarized in Table 1; for illustrations see Figure 3 ). To test the indication of a general promoting effect, we first tested the associations of optimism in the overall group. In support of Hypothesis 2, optimism showed a strong overall association with the baseline levels of both constructs: More optimistic adolescents showed higher academic achievement $(r=.27, S E=.066, p<.001)$ and self-esteem $(r=.19, S E$ $=.028, p<.001)$. With respect to predicting change toward the end of the 7th and 10th grades, the effects of optimism were rather small and not statistically significant in the overall group (see Table 1).

To further explore the relations involving optimism, we tested the interactions by comparing parameter estimations between groups (i.e., differential effects for adolescents with or without parental separation; Hypothesis 3). In line with our hypotheses, the results indicated differential effects of optimism between the two groups regarding academic achievement (for an overview, see also Table 1). Adolescents with nonseparated parents showed positive relations between optimism and academic achievement at baseline $(r=.28 ; S E=.055$, $p<.001)$ but no associations between optimism and change during the 7 th grade $(b=.03, S E=.056, p=.591)$, nor regarding the relation between optimism and change from the 7th to the 10th grades $(b=-.08, S E=.052, p=.123)$. Adolescents whose parents had separated demonstrated no connection between optimism and academic achievement at baseline $(r=.08, S E=.096, p=.412)$, but findings suggested a statistically significant prediction of optimism on the change in academic achievement during seventh grade $(b=.42, S E=.177$, $p=.018)$. The positive prediction of optimism on the difference score of academic achievement between the 7th and the 10th grades showed no statistical significance $(b=.27, S E=$ $.287, p=.349$ ). Comparing parameter estimations between the groups, we found no differences regarding the link between optimism and academic achievement at baseline $(\Delta r=.20$, $p=.329$ ). However, we found a larger impact of optimism on change in academic achievement during the seventh grade in the separation group $(\Delta b=-.39, p=.032)$. Differences 


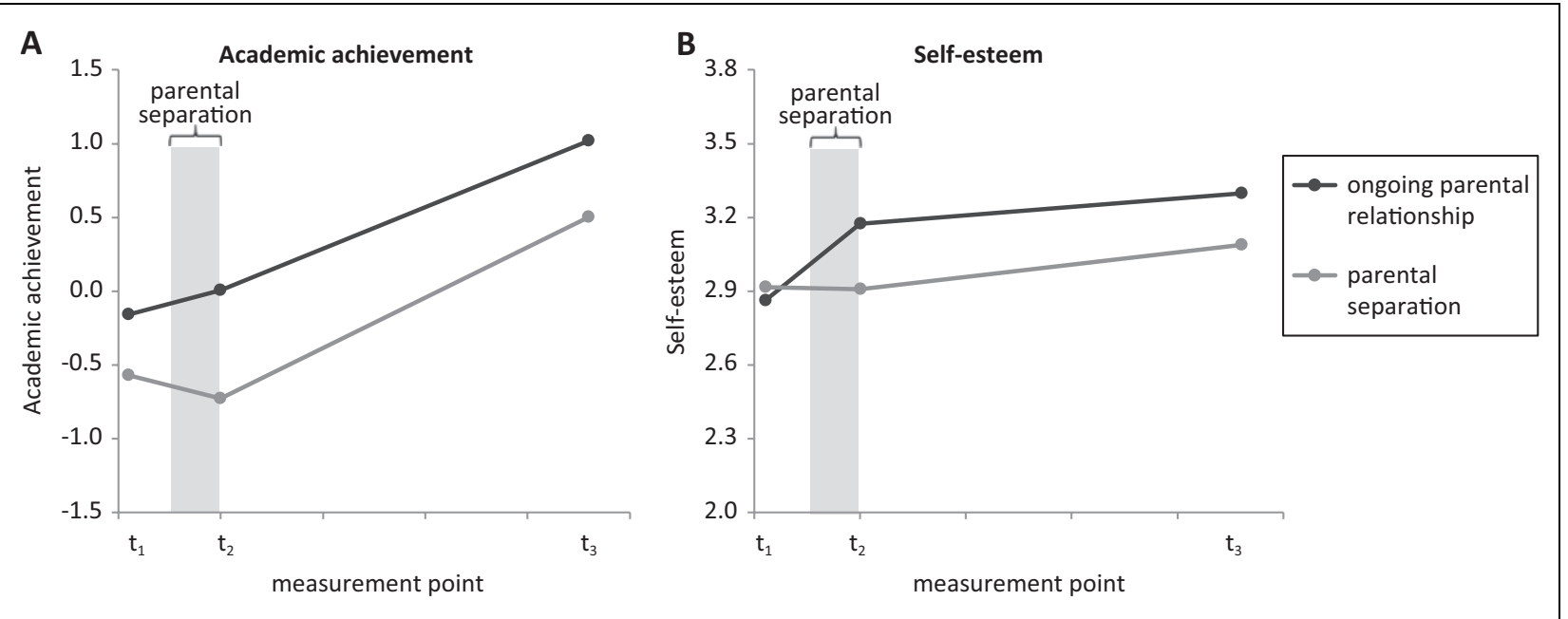

Figure 2. Mean-level changes in academic achievement and self-esteem from the beginning of the 7th grade to the end of the 10 th grade separated by parental relationship status.

Table I. Associations Between Optimism and Developmental Trajectories.

\begin{tabular}{|c|c|c|c|c|c|c|}
\hline \multirow[b]{3}{*}{ Construct/sample } & \multicolumn{6}{|c|}{ Effects of optimism on } \\
\hline & \multicolumn{2}{|c|}{$t_{1}$} & \multicolumn{2}{|c|}{ Difft2-t1 } & \multicolumn{2}{|c|}{$\operatorname{Diff}_{t 3-t \mid}$} \\
\hline & $b$ & $p$ & $b$ & $p$ & $b$ & $p$ \\
\hline \multicolumn{7}{|l|}{ Academic achievement } \\
\hline (a) Overall sample & .27 & $<.001$ & .03 & .435 & -.03 & .240 \\
\hline (b) Nonseparation group & .28 & $<.001$ & .03 & .591 & -.08 & .123 \\
\hline (c) Separation group & .08 & .412 & .42 & .018 & .27 & .349 \\
\hline Differences in estimations $(\Delta)$ & .20 & .329 & -.39 & .032 & -.35 & .057 \\
\hline \multicolumn{7}{|l|}{ Self-esteem } \\
\hline (a) Overall sample & .19 & $<.001$ & .02 & .770 & -.03 & .512 \\
\hline (b) Nonseparation group & .18 & $<.001$ & .02 & .697 & -.03 & .432 \\
\hline (c) Separation group & .25 & .025 & -.08 & .663 & .03 & .821 \\
\hline Differences in estimations $(\Delta)$ & -.07 & .453 & .10 & .810 & -.05 & .366 \\
\hline
\end{tabular}

Note. $t_{1}=$ correlations between optimism and baseline latent factors; Diff $t_{2-t 1}$ and Diff $_{\text {t3-tl }}=$ regression of change on optimism; Differences in estimations $(\Delta)=$ differences in standardized parameters between nonseparation and separation groups.

in the prediction of optimism on the change between $t_{1}$ and $t_{3}$ reached only marginal statistical significance $(\Delta b=-.35$, $p=.057$ ).

Contrary to our hypotheses, the results indicated no differential impact of optimism on trajectories of self-esteem according to parental relationship status. In both groups, optimism showed positive connections to the baseline measurement of self-esteem (nonseparation: $r=.18, S E=.035, p<.001$; separation: $r=.25, S E=.111, p=.025)$ but no relations to the change during the 7 th grade (nonseparation: $b=.02, S E=$ $.057, p=.697$; separation: $b=-.08, S E=.185, p=.663)$ and between the 7 th and the 10th grades (nonseparation: $b=-.03$, $S E=.034, p=.432$; separation: $b=.03, S E=.125, p=$
$.821)$. None of the differences in parameter estimations between the groups reached statistical significance $\left(\Delta b_{\text {baseline }}\right.$ $=-.07, p=.453 ; \Delta b_{\text {Difft } 1, t 2}=.10, p=.810 ; \Delta b_{\text {Difft } 1, t 3}=$ $-.05, p=.366)$.

Because we found differences in the baseline measurement for academic achievement, we estimated additional models using multivariate propensity score matching (PSM; e.g., Ho, Imai, King, \& Stuart, 2011; Thoemmes \& Kim, 2011) to control for baseline differences between the groups. PSM helps to increase internal validity, as it allows to distinguish the effects of parental separation on developmental trajectories more clearly from initial differences between the groups. Using matched samples, comparable on baseline covariates, the results remained statistically and substantially identical (results are available online as Supplemental Material).

Since previous studies reported effects of coping with parental separation by sex (e.g., McCabe, 1997) and educational status (e.g., Ross \& Mirowsky, 1999), we estimated additional models including these demographic background variables as covariates. These supplementary analyses produced virtually identical patterns of effects.

\section{Discussion}

This study aimed to contribute to the understanding of how adolescents adjust to parental separation in two salient aspects of development during adolescence, namely academic achievement and self-esteem. To do so, we focused specifically on the protective role of optimism.

Regarding the general impact of parental separation, our study showed that the separation of parents is a stressful life event that is associated with declines in developmental trajectories of adolescents. We therefore replicated findings, which showed that adolescents whose parents separate or divorce are at risk for 


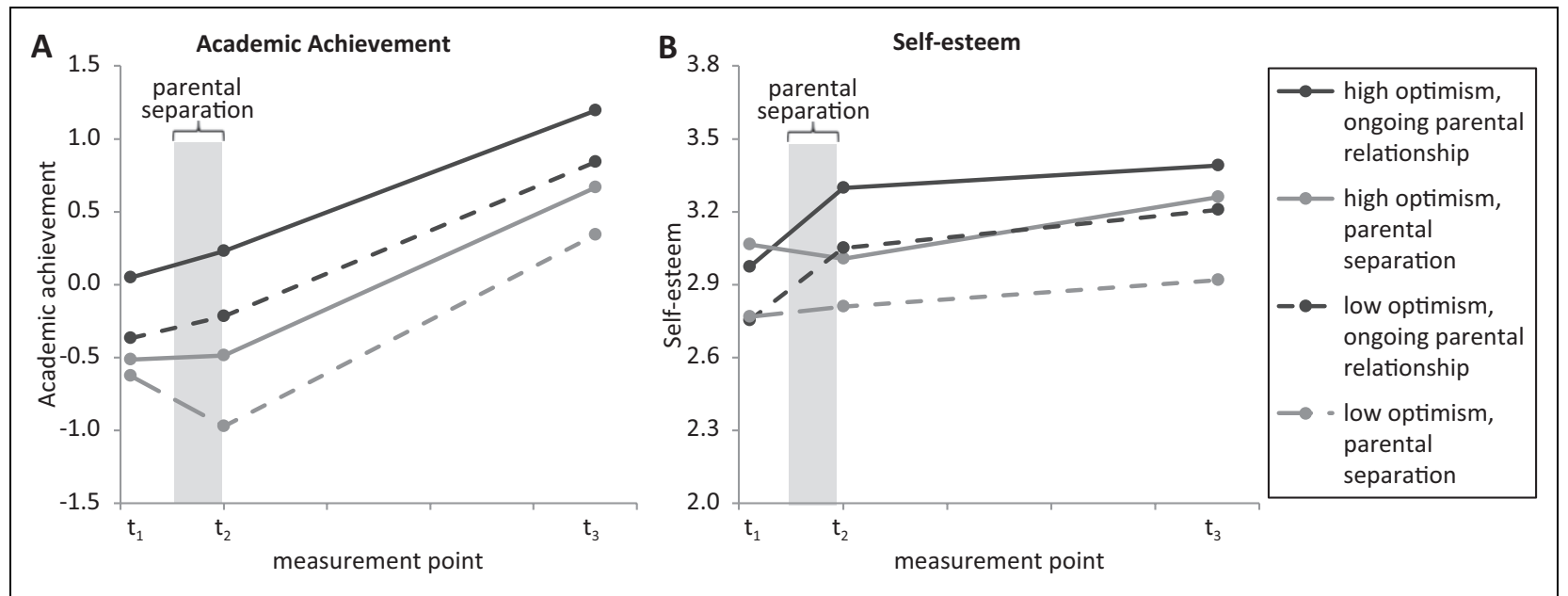

Figure 3. Mean-level changes in academic achievement and self-esteem from the beginning of the 7th grade to the end of the 10 th grade separated by parental relationship status and optimism.

Note. For graphical presentation, we picture two groups of optimism, namely, high optimism = I SD above average optimism; low optimism = I SD below average optimism.

various negative outcomes (cf. Amato, 2010; Hartman et al., 2011; Lansford, 2009). We found associations with academic achievement over shorter time periods and with self-esteem over shorter and longer time periods. Our findings are comparable with previous findings, as for example, Sun and $\mathrm{Li}$ (2002) also report a negative effect of parental separation on both academic achievement and self-esteem over a comparable time span.

Most importantly, our findings emphasize the beneficial role of optimism and highlight that optimism can support developmental trajectories in multiple ways: As predicted, we found a general promoting effect (i.e., a main effect) of optimism. On average, optimists accomplish greater achievement at school and report higher self-esteem, but optimism seems to have no general effects on changes in academic performance and self-esteem during adolescence. Yet, we found a specific beneficial impact of optimism that appears to unfold in the context of parental separation (i.e., interaction effects). More optimistic youth showed lesser declines in their academic achievement following parental separation than less optimistic youth, whereas optimism appeared to have no effect on developmental trajectories of youth with nonseparated parents. More precisely, optimism moderated the negative association between parental separation and academic achievement and acted as a protective factor in this specific domain.

Therefore, our findings highlight the general beneficial impact of optimism as well as the specific favorable effect for adolescents at risk and help to explain variability in reactions to the major life event of parental separation during this crucial period of life. Empirical studies already demonstrated generally beneficial effects of optimism on developmental trajectories as well as moderating effects of optimism on the adjustment to several stressful situations (cf. Carver et al., 2010), but no previous study showed that optimism seems to be an important factor for adolescents to cope more effectively with parental separation. One possible explanation for these beneficial relations could be that optimists may use more advantageous coping strategies that enable a better adjustment to adverse circumstances (Aspinwall \& Taylor, 1992; Brissette et al., 2002; Carver et al., 1993). Previous empirical studies indicated that optimism is positively related to approaching coping strategies that aim to manage consequences of stressors and problem-focused coping strategies that involve efforts to actively change or reduce stressors and demands (Nes \& Segerstrom, 2006). Building on this, optimism is an important resource for development in adolescence because it is associated with positive outcomes in general and helps to promote resilience in the face of significant adversity.

Moreover, the above-mentioned findings emphasize the importance and necessity of a conceptual differentiation between promoting and protective effects on developmental trajectories. As we found that more optimistic individuals show better adjustment to parental separation (i.e., protective effects), we found no overall beneficial effects (i.e., promoting effects) for this specific developmental period. Although many empirical studies fail to draw on such a distinction, it is essential to delineate general promoting effects on developmental trajectories from protective factors that enable individuals to adjust and adapt successfully after a negative life event or significant adversity (e.g., Keyes, 2004; Luthar et al., 2000).

In our study, we focused on associations with two highly relevant aspects of intraindividual development during adolescence, namely, academic achievement and self-esteem, and our results demonstrated that resilience against the negative impact of parental separation can vary with respect to several domains. Contrary to academic achievement, optimism did not moderate the negative association between parental separation and self-esteem. These results indicate that a factor that helps people to adjust better in one area appears to be not necessarily beneficial in others. Our findings therefore match current 
assumptions in the research on resilience, which postulates domain specificity in adjustment processes (Luthar et al., 2000). One explanation could be that self-esteem and academic achievement represent disparate demands (internal vs. external) that may require the use of different coping strategies (cf. Nes \& Segerstrom, 2006). Optimists should have an advantage in their adjustment to academic requirements, despite adversity because they use problem-focused coping strategies that help them to actively address external stressors and demands. However, maintaining self-esteem in the face of parental separation should rather involve emotion-focused coping strategies that are not necessarily more pronounced in optimists.

Some limitations of this study should also be noted. Although this longitudinal study used a large sample, some effects might be more subtle and are not detected due to test power. Even if our results suggest the practical importance of optimism for longer term changes in academic achievement after parental separation, this association failed to reach statistical significance. ${ }^{5}$ This may also explain why we did not find a clear long-term effect of parental separation on academic achievement ${ }^{6}$ as Sun and $\mathrm{Li}$ (2002) who found such a longer term effect.

In addition to declines in developmental trajectories associated with parental separation, we found differences in the baseline measurement for academic achievement. Baseline differences might be related to a different functionality in families (e.g., Strohschein, 2005; Sun \& Li, 2001) but following our results, they do not seem to depend on the families' economic resources. ${ }^{7}$ Amato (2010) speculated that this effect may be caused by increased stress due to frequent parental conflicts that precede separation. Although it seems plausible that parental separation can even cause effects before the event occurs, initial differences can challenge causal conclusions regarding effects following parental separation as other factors might be relevant for the differential trajectories being confounded with the treatment effect (e.g., baseline differences in academic achievement or parental socioeconomic status). However, we found the same pattern of results after controlling for baseline differences via PSM (for details, see the online Supplemental Material). As an additional limitation, due to the design of our study, we are not able to explain whether the (general) positive associations between the life outcomes and optimism (sensu promoting effects) are caused by high levels of optimism or vice versa.

Taken together, the results of this study contribute to the current knowledge of how young people are susceptible to and overcome such adversity as parental separation, especially during adolescence. They offer important insights into the role of optimism in developmental processes, explaining how individuals differ in their reactions to (severe) adversity in life, and thereby contribute to the literature on coping and resilience. To further expand our knowledge on the generality and specificity of resilience factors, future investigations should address the protective and promoting effects of optimism and related coping mechanisms with regard to variations in negative life events and other age-groups.

\section{Appendix}

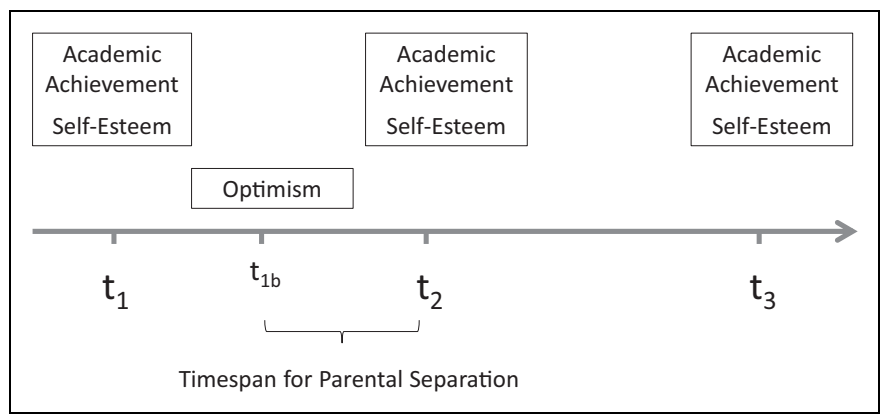

Figure A I. Design of the study. Note. $t_{1}=$ first measurement point at the beginning of the 7th grade; $t_{2}=$ second measurement point at the end of the 7 th grade (short-term associations); $t_{3}=$ third data collection point at the end of the 10th grade (longer term associations); and $t_{\mathrm{lb}}=$ additional measurement point midway through the 7 th grade.

\section{Declaration of Conflicting Interests}

The author(s) declared no potential conflicts of interest with respect to the research, authorship, and/or publication of this article.

\section{Funding}

The author(s) received no financial support for the research, authorship, and/or publication of this article.

\section{Notes}

1. McCabe (1997) found long-term effects of divorce in childhood on depression in young adulthood for women but not for men.

2. Early parental divorce (during kindergarten through to Grade 5) was more negatively related to trajectories of internalizing and externalizing problems, whereas later divorce/separation (Grades 6-10) was more negatively related to academic grades.

3. Vélez and colleagues (2011) found positive effects of interventioninduced improvements in mother-child relationship quality in postdivorced families on children's coping processes.

4. Optimism did not correlate statistically significant with following parental separation $(r=-.06 ; p=.057)$.

5. The required sample size for detecting this medium-sized effect ( $b=.27$; cf. Cohen, 1988) as statistically significant (two-tailed test, $\alpha=.05$ ) amounts to $n=168$ (see G*Power 3.1; Faul, Erdfelder, Lang, \& Buchner, 2007).

6. This small effect of $d=.14$ (Cohen, 1988) would require a sample size of $n=664$ in each group to be detected using a two-tailed significance test with $\alpha=.05$ (see G*Power 3.1; Faul et al., 2007).

7. In our sample, the association between parental socioeconomic status and parental separation was not statistically significant $(r=-.03, p=.524)$.

\section{Supplemental Material}

The online supplemental material is available at http://spps.sagepub. com/supplemental. 


\section{References}

Amato, P. R. (2010). Research on divorce: Continuing trends and new developments. Journal of Marriage and Family, 72, 650-666. doi: 10.1111/j.1741-3737.2010.00723.x

Andersson, G. (1996). The benefits of optimism: A meta-analytic review of the life orientation test. Personality and Individual Differences, 21, 719-725. doi:10.1016/0191-8869(96)00118-3

Aspinwall, L. G., \& Taylor, S. E. (1992). Modeling cognitive adaptation: A longitudinal investigation of the impact of individual differences and coping on college adjustment and performance. Journal of Personality and Social Psychology, 63, 989-1003. doi:10.1037/0022-3514.63.6.989

Baltes, P. B., Lindenberger, U., \& Staudinger, U. M. (2006). Life span theory in developmental psychology. In W. Damon \& R. M. Lerner (Eds.), Handbook of child psychology: Vol. 1. Theoretical models of human development (6th ed., pp. 569-664). New York, NY: John Wiley.

Becker, M., Lüdtke, O., Trautwein, U., Köller, O., \& Baumert, J. (2012). The differential effects of school tracking on psychometric intelligence: Do academic-track schools make students smarter? Journal of Educational Psychology, 104, 682-699. doi:10.1037/a0027608

Brim, O. G., \& Ryff, C. D. (1980). On the properties of life events. In P. B. Baltes \& O. G. Brim (Eds.), Life-span development and behavior (pp. 367-388). New York, NY: Academic Press.

Brissette, I., Scheier, M. F., \& Carver, C. S. (2002). The role of optimism in social network development, coping, and psychological adjustment during a life transition. Journal of Personality and Social Psychology, 82, 102-111. doi:10.1037/0022-3514.82.1.102

Bynum, M. K., \& Durm, M. W. (1996). Children of divorce and its effect on their self-esteem. Psychological Reports, 79, 447-450. doi:10.2466/pr0.1996.79.2.447

Carver, C. S., \& Connor-Smith, J. (2010). Personality and coping. Annual Review of Psychology, 61, 679-704. doi:10.1146/ annurev.psych.093008.100352

Carver, C. S., Pozo, C., Harris, S. D., Noriega, V., Scheier, M. F., Robinson, D. S., . . Clark, K. C. (1993). How coping mediates the effect of optimism on distress: A study of women with early stage breast cancer. Journal of Personality and Social Psychology, 65, 375-390. doi:10.1037/0022-3514.65.2.375

Carver, C. S., Scheier, M. F., \& Segerstrom, S. C. (2010). Optimism. Clinical Psychology Review, 30, 879-889. doi:10.1016/j.cpr.2010.01.006

Cohen, J. (1988). Statistical power analysis for the behavioral sciences (2nd ed.). Hillsdale, NJ: Lawerence Erlbaum.

Collins, L. M., Schafer, J. L., \& Kam, C.-M. (2001). A comparison of inclusive and restrictive strategies in modern missing data procedures. Psychological Methods, 6, 330-351. doi:10.1037/1082-989X.6.4.330

Faul, F., Erdfelder, E., Lang, A.-G., \& Buchner, A. (2007). G*Power 3: A flexible statistical power analysis program for the social, behavioral, and biomedical sciences. Behavior Research Methods, 39, 175-191. doi:10.3758/BF03193146

Fergusson, D. M., McLeod, G., \& Horwood, J. L. (2014). Parental separation/divorce in childhood and partnership outcomes at age 30. Journal of Child Psychology and Psychiatry, 55, 352-360. doi:10.1111/jcpp.12107

Frisco, M. L., Muller, C., \& Frank, K. (2007). Parents? Union dissolution and adolescents? School performance: Comparing methodological approaches. Journal of Marriage and Family, 69, 721-741. doi:10.1111/j.1741-3737.2007.00402.x

Graham, J. W. (2009). Missing data analysis: Making it work in the real world. Annual Review of Psychology, 60, 549-576. doi:10. 1146/annurev.psych.58.110405.085530

Ham, B. D. (2003). The effects of divorce on the academic achievement of high school seniors. Journal of Divorce \& Remarriage, 38, 167-185. doi:10.1300/J087v38n03_09

Hartman, L. R., Magalhães, L., \& Mandich, A. (2011). What does parental divorce or marital separation mean for adolescents? A scoping review of north American literature. Journal of Divorce \& Remarriage, 52, 490-518. doi:10.1080/10502556.2011.609432

Hetherington, E. M. (2006). The influence of conflict, marital problem solving and parenting on children's adjustment in nondivorced, divorced and remarried families. In A. Clarke-Stewart \& J. Dunn (Eds.), Families count (pp. 203-237). Cambridge, England: Cambridge University Press.

Hetherington, E. M., \& Stanley-Hagan, M. (1999). The adjustment of children with divorced parents: A risk and resiliency perspective. Journal of Child Psychology and Psychiatry, 40, 129-140. doi: 10.1111/1469-7610.00427

Ho, D. E., Imai, K., King, G., \& Stuart, E. A. (2011). MatchIt: Nonparametric preprocessing for parametric causal inference. Journal of Statistical Software, 42, 1-28.

Jerusalem, M. (1984). Selbstbezogene Kognitionen in schulischen Bezugsgruppen - Eine Längsschnittstudie [Self-related cognitions in school contexts]. Berlin, Germany: Freie Universität, Institut für Psychologie.

Jeynes, W. H. (2002). Does parental involvement eliminate the effects of parental divorce on the academic achievement of adolescents? Journal of Divorce \& Remarriage, 37, 101-115. doi:10.1300/ J087v37n01_06

Keyes, C. (2004). Risk and resilience in human development: An introduction. Research in Human Development, 1, 223-227. doi: 10.1207/s15427617rhd0104_1

Kivimäki, M., Vahtera, J., Elovainio, M., Helenius, H., SinghManoux, A., \& Pentti, J. (2005). Optimism and pessimism as predictors of change in health after death or onset of severe illness in family. Health Psychology, 24, 413-421. doi:10.1037/ 0278-6133.24.4.413

Lansford, J. E. (2009). Parental divorce and children's adjustment. Perspectives on Psychological Science, 4, 140-152. doi:10.1111/ j.1745-6924.2009.01114.x

Lansford, J. E., Malone, P. S., Castellino, D. R., Dodge, K. A., Pettit, G. S., \& Bates, J. E. (2006). Trajectories of internalizing, externalizing, and grades for children who have and have not experienced their parents' divorce or separation. Journal of Family Psychology, 20, 292-301. doi:10.1037/0893-3200.20.2.292

Litt, M. D., Tennen, H., Affleck, G., \& Klock, S. (1992). Coping and cognitive factors in adaptation to in vitro fertilization failure. Journal of Behavioral Medicine, 15, 171-187. doi:10.1007/BF00848324

Little, R., \& Rubin, D. B. (2002). Statistical analysis with missing data. New York, NY: John Wiley.

Lucas, R. E. (2007). Adaptation and the set-point model of subjective well-being: Does happiness change after major life events? Current Directions in Psychological Science, 16, 75-79. doi:10. 1111/j.1467-8721.2007.00479.x 
Luthar, S. S., Cicchetti, D., \& Becker, B. (2000). The construct of resilience: A critical evaluation and guidelines for future work. Child Development, 71, 543-562. doi:10.1111/1467-8624.00164

Mandara, J., \& Murray, C. B. (2000). Effects of parental marital status, income, and family functioning on African American adolescent self-esteem. Journal of Family Psychology, 14, 475-490. doi:10. 1037//0893-3200.14.3.475

McArdle, J. J. (2009). Latent variable modeling of differences and changes with longitudinal data. Annual Review of Psychology, 60, 577-605. doi:10.1146/annurev.psych.60.110707.163612

McArdle, J. J., \& Hamagami, F. (2001). Latent difference score structural models for linear dynamic analysis with incomplete longitudinal data. In L. M. Collins \& A. G. Sayer (Eds.), New methods for the analysis of change (pp. 139-175). Washington, DC: American Psychological Association.

McCabe, K. M. (1997). Sex differences in the long term effects of divorce on children. Journal of Divorce \& Remarriage, 27, 123-135. doi:10.1300/J087v27n01_08

McLanahan, S. S. (1999). Father absence and the welfare of children. In E. M. Hetherington (Ed.), Coping with divorce, single parenting, and remarriage: $A$ risk and resiliency perspective (pp. 117-146). Hillsdale, NJ: Erlbaum.

Menning, C. L. (2006). Nonresident fathering and school failure. Journal of Family Issues, 27, 1356-1382. doi:10.1177/ 0192513X06290038

Meredith, W. (1993). Measurement invariance, factor-analysis and factorial invariance. Psychometrika, 58, 525-543. doi:10.1007/ Bf02294825

Muthén, L. K., \& Muthén, B. O. (1998-2011). Mplus user's guide (6th ed.). Los Angeles, CA: Author.

Nes, L. S., \& Segerstrom, S. C. (2006). Dispositional optimism and coping: A meta-analytic review. Personality and Social Psychology Review, 10, 235-251. doi:10.1207/s15327957pspr1003_3

Pong, S.-L., \& Ju, D.-B. (2000). The effects of change in family structure and income on dropping out of middle and high school. Journal of Family Issues, 21, 147-169. doi:10.1177/019251300021002001

R Core Team (2014). R: A language and environment for statistical computing. Vienna, Austria: R Foundation for Statistical Computing. Retrieved from http://www.R-project.org

Robinson, M. D., \& Liu, T. (2013). Perceptual negativity predicts greater reactivity to negative events in daily life. Personality and Individual Differences, 55, 926-930. doi:10.1016/j.paid.2013.07.468

Rosenberg, M. (1965). Society and the adolescent self-image. Princeton, NJ: Princeton University Press.

Ross, C. E., \& Mirowsky, J. (1999). Parental divorce, life-course disruption, and adult depression. Journal of Marriage and the Family, 61, 1034-1045. doi:10.2307/354022

Scheier, M. F., \& Carver, C. S. (1985). Optimism, coping, and health: Assessment and implications of generalized outcome expectancies. Health Psychology, 4, 219-247. doi:10.1037/0278-6133.4.3.219

Scheier, M. F., Matthews, K. A., Owens, J. F., Magovern, G. J., Lefebvre, R. C., Abbot, R. A., \& Carver, C. S. (1989). Dispositional optimism and recovery from coronary artery bypass surgery: The beneficial effects on physical and psychological well-being. Journal of Personality and Social Psychology, 57, 1024-1040. doi:10.1037/0022-3514.57.6.1024
Schnabel, K. U., Alfeld, C., Eccles, J. S., Köller, O., \& Baumert, J. (2002). Parental influence on students' educational choices in the United States and Germany: Different ramifications-Same effect? Journal of Vocational Behavior, 60, 178-198. doi:10. 1006/jvbe.2001.1863

Sigle-Rushton, W., Lyngstad, T. H., Andersen, P. L., \& Kravdal, Ø. (2014). Proceed with caution? Parents' union dissolution and children's educational achievement. Journal of Marriage and Family, 76, 161-174. doi:10.1111/jomf.12075

Snijders, T., \& Bosker, R. J. (1999). Multilevel analysis: An introduction to basic and advanced multilevel modeling. London, UK: Sage.

Strohschein, L. (2005). Parental divorce and child mental health trajectories. Journal of Marriage and Family, 67, 1286-1300. doi: 10.1111/j.1741-3737.2005.00217.x

Sun, Y., \& Li, Y. (2001). Marital disruption, parental investment, and children's academic achievement: A prospective analysis. Journal of Family Issues, 22, 27-62. doi:10.1177/019251301022001002

Sun, Y., \& Li, Y. (2002). Children's well-being during parents' marital disruption process: A pooled time-series analysis. Journal of Marriage and Family, 64, 472-488. doi:10.1111/j.1741-3737. 2002.00472.x

Thoemmes, F. J., \& Kim, E. S. (2011). A systematic review of propensity score methods in the social sciences. Multivariate Behavioral Research, 46, 90-118. doi:10.1080/00273171.2011.540475

Trautwein, U. (2003). Schule und Selbstwert [Schools and selfesteem]. Münster, Germany: Waxmann.

Treiman, D. J. (1977). Occupational prestige in comparative perspective. New York, NY: Academic Press.

van Buuren, S., \& Groothuis-Oudshoorn, K. (2011). MICE: Multivariate imputation by chained equations in R. Journal of Statistical Software, 45, 1-67.

Vélez, C. E., Wolchik, S. A., Tein, J.-Y., \& Sandler, I. (2011). Protecting children from the consequences of divorce: A longitudinal study of the effects of parenting on children's coping processes. Child Development, 82, 244-257. doi:10.1111/j.1467-8624.2010.01553.x

Wieland-Eckelmann, R., \& Carver, C. (1989). Dispositionelle Angstbewältigungsstile, Optimismus und Bewältigung: Ein interkultureller Vergleich. [Dispositional styles of coping with anxiety, optimism and coping: an intercultural comparison]. Zeitschrift für Differentielle und Diagnostische Psychologie, 11, 167-184.

Wrosch, C., \& Freund, A. M. (2001). Self-regulation of normative and non-normative developmental challenges. Human Development, 44, 264-283. doi:10.1159/000057066

\section{Author Biographies}

Julia Tetzner is a research scientist at the University of Potsdam. She is particularly interested in the psychosocial development in adolescence and young adulthood and the interplay of risk and protective factors.

Michael Becker is a senior researcher at the German Institute for International Educational Research (DIPF) at the Department of Educational Governance. His research revolves around cognitive and psychosocial development from childhood to young adulthood, the interplay between individual characteristics and environmental structures, and the psychological and sociological effects of educational and professional transitions. 